\title{
Application and Discussion of LBL Combined with PBL Mode in the Histoembryology Teaching
}

\author{
Yanling Sun ${ }^{1 *}$, Jianguo $\mathbf{L v}^{2}$ \\ ${ }^{1}$ Basic Medical School, Hubei University of Science and Technology, Xianning 437100, Hubei, China. E-mail: \\ sunstonesyl@163.com \\ ${ }^{2}$ Clinical Medical School \& Second Affiliated Hospital, Hubei University of Science and Technology, Xianning 437100, Hubei, \\ China.
}

Project: Hubei University of Science and Technology Key Project of Teaching Research(2017-XA-005)

Abstract: Histoembryology are closely related to disease prevention, diagnosis and treatment, which is a connecting subject between basic medicine and clinical medicine, and plays very important role in medical teaching. This paper mainly focuses on the teaching mode of Histoembryology, analyzes the teaching characteristics of traditional LBL teaching mode and current mainstream PBL teaching mode, and states the application steps of LBL combined with PBL mode in Histoembryology teaching, so that we can understand the focus of PBL teaching mode more clearly. Finally, the application effect of PBL mode in the teaching of Histoembryology is discussed through the application effect. The conclusion shows that the double track teaching mode of LBL combined with PBL is very effective in the teaching of Histoembryology.

Keywords: LBL Combined with PBL Teaching Mode; Histoembryology; Teaching Effect

Histoembryology is the first professional subject that medical students come into contact with, and it is also a basic medical discipline. It involves a large number of complicated courses. In the traditional LBL teaching mode, students can passively accept a great amount of professional theoretical knowledge, but it is easy to produce memory fatigue and the overall learning effect is not good. As soon as currently international recognized PBL teaching mode is introduced, it has been recognized by medical teaching workers. The integration of PBL double track teaching mode in traditional LBL can greatly stimulate students' learning initiative and improve their ability to analyze and solve problems. Good teaching effect has been achieved in the teaching practice of Histoembryology.

\section{The teaching characteristics of $L B L$ and PBL}

\subsection{Characteristics of LBL teaching mode}

The full name of LBL is lecture-based learning, which is a traditional teaching method based on teaching, and taught by teachers in the classroom during the teaching process. This teaching mode is still widely used in medical teaching. Its biggest feature is that it can impart the students the basic knowledge with the maximum amount of information in the limited class time, which is necessary for the extensive and profound professional knowledge of medical disciplines. However, its disadvantage is that the students passively accept the instillation of knowledge, which easily leads to memory fatigue, even weariness of learning, and insufficient subjective initiative in learning.

Copyright(C) 2020 Yanling Sun et al.

doi: 10.18686/ahe.v4i10.2915

This is an open-access article distributed under the terms of the Creative Commons Attribution Non-Commercial License (http://creativecommons. org/licenses/by-nc/4.0/), which permits unrestricted non-commercial use, distribution, and reproduction in any medium, provided the original work is properly cited. 


\subsection{Characteristics of PBL teaching mode}

The full name of PBL is problem-based Learning, which is a modern teaching method based on problems, was proposed by Howard barrows, an American professor, as early as 1969. In PBL mode, the teaching center is changed from a teacher to a student. The teacher puts forward relevant questions according to the course content, and then leads the students alone or in groups to consult the data, discuss and verify with each other, and finally find the right answer by the guidance of teacher. PBL teaching mode has greatly mobilized students' learning autonomy and enthusiasm, and in the process of exploring answers, it has cultivated students' ability to analyze and solve problems. Based on these advantages, PBL mode has become the mainstream teaching method in medical education.

\section{The teaching steps of LBL combined with PBL in the course of Histoembryology}

Histoembryology is a basic subject for medical students to study other medical courses. It mainly teaches students to study the micro structure and function of human body by using microscope technology. The professional knowledge involved in this subject is relatively abstract and obscure, which easily makes students fear difficulties and lose interest in learning. On the basis of LBL combined with PBL teaching mode, it is a new attempt for teachers to improve the quality of teaching

LBL combined with PBL mode is to complete the teaching of basic organization chapters with LBL, and then carry out PBL teaching on this basis. It can be divided into the following specific steps: (1) A week in advance through the network platform to upload the relevant key theoretical knowledge of the micro class, give students two days to digest, and complete the test questions in the micro class; (2) Select a clinical case related the teaching content to arouse students' interest, then put forward related questions, recommend relevant references, in order to encourage students to search and sort out the data according to their own needs, and prepare their own answers; (3) In the classroom, teachers sort out and summarize the theoretical knowledge of the course, and emphasize the important and difficult parts again, which is convenient for students to deepen their understanding and memory; (4) The students were randomly divided into groups, and each group member shared the information they had searched and the answers they had got. Other members of the group should put forward their own opinions on this. Everyone should correct and supplement each other. The teacher commented on the final discussion results. Finally, each student writes a small paper according to the results, which is counted as the assignment of this class Students' usual grades. After Histoembryology teaching by LBL combined with PBL mode, the teacher found that the qualified rate is significantly improved compared with the previous LBL teaching.

\section{The application effect of LBL combined with PBL in the teaching of Histoembryology}

\subsection{Improve students' autonomous learning ability}

The biggest characteristic of PBL teaching mode is that students are the center. Teachers put forward questions to guide students to look up and sort out data around the problems, and seriously think about the answers to the questions. In this process, students can face, analyze and solve a problem, which is different from the traditional LBL teaching mode that is taught by teachers all the time. Students should not wait for the answer, so they have to find it by themselves. Therefore, in order to complete the tasks assigned by teachers, students' learning enthusiasm is greatly mobilized, and the ability of autonomous learning is improved.

\subsection{Enhance students' interpersonal skills}

PBL teaching mode is to let students search literature around the problem, think independently and find the right answer. This part can improve students' autonomous learning ability. After completing their answers, there is also a group discussion session in PBL teaching. In this teaching session, each group as a small group discusses with each other. As a social platform, everyone can state their own answers, so as to improve their language expression ability and the courage to speak to others. At the same time, we also need to put forward opinions on the answers of other group members. In these communications, students' interpersonal skills can be enhanced and complement and improve the answers together. It is conducive to the cultivation of students' team spirit, which is very beneficial to the improvement of students' comprehensive quality, and it is also beneficial for students to go to work in the future and contact with colleagues and patients. 


\subsection{Improve the teaching effect of course content}

In PBL teaching mode, students need to find relevant literature and understand and digest the literature when completing the tasks assigned by teachers. In this process, students need to repeatedly interpret relevant knowledge points, which not only deepens students' impression of relevant theories and expands their knowledge capacity in literature search, but is also an improvement of teaching effect of course content.

\section{Disadvantages of LBL combined with PBL mode in the teaching of Histoembryology}

\subsection{Less teaching content}

Compared with LBL teaching mode, PBL teaching mode pays more attention to the improvement of students' autonomous learning ability and problem-solving ability, but it has less coverage in teaching content. For the huge theoretical knowledge system of Histoembryology course, it is easy to cause students' theoretical foundation is not solid, which is not conducive to further development for students.

\subsection{More class hours}

PBL teaching mode requires more class hours. It also requires teachers to arrange questions in advance, give students plenty of time to search literature, summarize and summarize, and carry out group discussion in class. The development of these teaching activities will cost a lot of class hours. In view of the large amount of teaching content to be completed in limited class hours, it is not realistic to change the teaching mode from LBL to PBL.

\subsection{Weak Students' autonomous ability}

The successful development of PBL teaching mode largely depends on the students' autonomous learning ability. However, for medical students, Histoembryology is an unfamiliar subject, and the professional knowledge involved is relatively obscure. In addition, they have been used to LBL mode in the previous study, so students cannot adapt to PBL teaching mode with weak autonomous learning ability. Fortunately, most of the students agree with the PBL teaching mode and think it is helpful for their own learning. They have begun to actively try to accept this new mode. According to the survey of students, it is generally believed that the best way is to adopt the double track teaching mode of LBL combined with PBL, leaving students with a time to adapt.

\section{Conclusion}

The teaching practice has proved that the double track teaching mode integrating PBL into LBL traditional teaching mode is very effective. On the basis of teaching students solid professional theory, it provides students with more sufficient autonomous learning space, which is very beneficial to stimulate students' learning enthusiasm and exploration spirit. This teaching mode is completely suitable for the teaching of Histoembryology. It can complete the transition from basic courses to clinical courses, and it not only lays a solid theoretical knowledge foundation for students, but also cultivates students' comprehensive quality. It opens a new door for medical personnel training, which is worthy of further discussion. However, according to the current learning situation of medical students in our country, it still needs a step-by-step process to fully implement the PBL teaching mode, so that students can slowly adapt to it.

\section{References}

1. Sui $\mathrm{H}$, Zheng $\mathrm{H}$, Zhao S, et al. Application of hybrid teaching method in histology and embryology teaching of clinical medicine undergraduates. Chinese Higher Medical Education 2018; (12): 104-105.

2. Cheng J. Effect analysis of PBL combined with LBL teaching method in clinical teaching of gastroenterology. Chinese Health Industry 2020; 17(18): 146-148. 